\title{
Miradas transdisciplinarias en las ciencias sociales en América Latina. Reflexiones que se articulan con los conceptos de autonomía y alteridad desarrollados por Cornelius Castoriadis*
}

\author{
María del Socorro Foio*
}

\section{Resumen}

En este artículo reflexionamos acerca del papel de la universidad y las ciencias sociales en Latinoamérica, y sus posibilidades para crear conocimiento con otros -enseñando y aprendiendo a la vez-, en una revisión teórica y metodológica que, incluyendo la discusión con la crítica de la colonialidad, habilite la construcción transdisciplinaria.

Entendemos que las nociones de autonomía y alteridad desarrolladas por Castoriadis son fructíferas para imaginar unas ciencias sociales-otras, cuyo desafío es fisurar aquellos mecanismos de subvaloración de vidas y saberes impuestos en

* Artículo recibido el 18 de julio de 2014. Aceptado el 17 de noviembre de 2014.

Este artículo reconoce sus orígenes en los contenidos desarrollados e intercambios producidos en las sesiones virtuales, así como en las lecturas de la bibliografía correspondientes al cursado en 2013 de los Seminarios "Sociedad instituyente y clínica de la alteridad: un acercamiento a la obra institucional de Castoriadis (cuarta fase)", con sede en la Universidad Autónoma Metropolitana-Unidad Xochimilco, coordinado por el Dr. Rafael Miranda Redondo, y "El Proyecto de autonomía hoy", con sede en PROIMMSE-IIA, UAM, coordinado por el Dr. Miranda Redondo en forma conjunta con la Dra. Dolores Camacho.

* María del Socorro Foio es Licenciada en Sociología; Magíster en Epistemología y Metodología de la Investigación Científica por la Universidad Nacional del Nordeste.

Correo electrónico: socorrofoio@gmail.com 
nuestro continente por la herencia monocultural del colonialismo y los Estados-nación y la lógica del mercado. En ese marco, repasamos algunas teorías y constructos conceptuales que, en la recuperación de lógicas de pensamiento, formas de socialización y subjetividad presentes en pueblos originarios y afroamericanos y sectores subalternos rurales y urbanos, resignifican el legado de epistemologías subordinadas y las prácticas de colectivos sociales que luchan por otros mundos posibles.

\section{Palabras clave}

Procesos de creación - Destrucción/emergencia radical Diálogo de saberes - Proyecto de autonomía individual y colectiva.

\section{Abstract}

This article examines the role of the university and social sciences in Latin America, and its possibilities to create knowledge with others -teaching and learning at the same time-, in a theoretical and methodological revision that, including the discussion with theories of the colonialism, it enables the transdisciplinary construction.

We appreciate that the notions of autonomy and alterity introduced by Castoriadis are fruitful to imagine social sciencesothers. Their challenge is to break those mechanisms of sub valuation of lives and knowledge imposed in our continent by the monocultural inheritance of the colonial period and the State-nation, and the market's logic.

In addition we review some theories and conceptual constructs that in the recovery of existent logics of thought, forms of socialization and subjectivity in native and Afro-American communities and subordinated rural and urban sectors, they produce new meanings about the legacy of the subordinated epistemologies and the practices of social groups that fight by other possible worlds.

\section{Keywords}

Processes of creation/destruction/radical emergency - Dialogue of knowledge - Project of individual and collective autonomy. 


\section{Imaginario e institución. Una breve introducción}

Forjada al calor de las movilizaciones y debates en la Francia posterior a la Segunda Guerra Mundial, la obra escrita y la labor institucional de Cornelius Castoriadis halló un importante sustento en la teoría y la práctica psicoanalíticas.

En su trabajo más comprehensivo, La institución imaginaria de la sociedad, editado en 1975, Castoriadis emprende la búsqueda, conceptualización y examen crítico de los significados primarios organizadores de un modo de ser lo social -las significaciones imaginarias sociales (SIS). En tanto universos de significaciones que establecen el sentido preciso de cada época, las SIS cobran cuerpo en la institución de la sociedad, la orientan y la rigen y, a la vez, refieren a la facultad de innovación radical, de formación de todo lo que aparece como realidad. "Únicamente la institución de la sociedad que procede del imaginario social puede limitar la imaginación radical de la psique y dar existencia para esta a una realidad, al dar existencia a una sociedad" (Castoriadis, 2007, p. 483).

De aquí se desprenden dos ideas sustantivas: la fuerza de la imaginación como creadora de instituciones, y la sociedad como correlato único posible de la vida del individuo, ideas que darán cuenta de las tensiones entre sujeto y sociedad, consciente e inconsciente, imaginario radical e imaginario social, lenguaje y acción.

Las significaciones no son lo que los individuos se representan consciente o inconscientemente, ni lo que piensan, sino que son "condiciones de lo representable y de lo factible" $(2007,567)$ y por lo tanto se trata de algo "inconcebible como obra o producto de un individuo o de una multitud de individuos, inderivable a partir de la psique como tal" $(2007,391)$.

En el ingreso de la psique al mundo se pone por encima la institución social, ocultando la autocreación de la sociedad (Miranda Redondo, 2006). La unidad de aquella institución está dada por el magma de SIS con orígenes en lo histórico-social, lo que permite mantener la cohesión y crear nuevas realidades (Castoriadis, 1996b).

Al conformar las significaciones un "haz de remisiones interminables a otra cosa" (2007, 386), todo el magma de SIS en cada sociedad se halla en una relativa indeterminación que posibilita tanto la permanencia de lo instituido como la aparición de nuevos instituyentes en la creación de simbolismos y que, en su dinámica, generan historia.

En tanto ser histórico-social, el individuo es un sujeto que ha interiorizado la totalidad de la institución socialmente dada, así como las SIS. Las alternativas a los posicionamientos de ese sujeto, la autonomía y la heteronomía, son planteadas por Castoriadis en Dominios del Hombre: Encrucijadas del laberinto II y El Mundo 
Fragmentado. Encrucijadas del laberinto III, publicados en 1986 y 1993, respectivamente.

Empecemos por la heteronomía, principio que entraña la sumisión a normas y prácticas que son obedecidas sin haber sido creadas por la sociedad que las acata. Cuando la socialización opera, la imaginación radical del sujeto -individual o colectivose encuentra limitada, adquiriendo un carácter de conformidad y de repetición; todas las preguntas formulables son respondidas en el marco de las SIS, mientras que las que no pueden ser contestadas son, más que prohibidas, imposibles de presentarse mental y psíquicamente, asegurando de esta manera la reproducción de las estructuras sociales.

Las respuestas a los interrogantes que están en el origen de la autoinstitución de la sociedad, ¿quiénes somos? ¿Qué queremos? ¿Por qué y para qué existimos? delimitan las fronteras de esa sociedad, donde lo otro, lo ajeno -la alteridad- se constituye como ausencia de sentido. Es decir, que la institución se erige en frontera mediante las SIS plasmadas en una cultura de la organización social (Miranda Redondo, 2010b).

\section{Multiplicidad del ser: diferencia y alteridad}

Cabe introducir aquí, someramente, los fundamentos filosóficos que sustentan la noción de alteridad propuesta por Castoriadis en El Mundo Fragmentado. Encrucijadas del laberinto III, publicado en 1993, donde confrontará su perspectiva ontológica con la concepción conjuntista que moldeó el pensamiento moderno occidental.

Tanto en la ontología hegeliana como en el positivismo, el ser es uno no solo lógica y nominalmente, sino también efectivamente. La pluralidad de los entes particulares se agrupa en una unidad por las leyes que producen y deducen los entes, unos a partir de otros. La multiplicidad en el ser existe como diferencia; las cualidades son cuantificables, y las cantidades diferentes dan lugar a cualidades -reductiblesdiferentes.

Castoriadis cuestionará esa concepción ontológica al sostener que si bien la multiplicidad del ser existe como diferencia -lo que implica identidad, persistencia, repetición-, también existe como alteridad -lo que entraña procesos de creación y destrucción de formas.

En lo que concierne a la destrucción, hace mención a la tendencia entrópica, pero advierte que las formas no son solamente destruidas, sino que también son creadas. Ello obliga a distinguir entre diferencia y alteridad: dos objetos son diferentes si existe un conjunto de transformaciones determinadas, o leyes, que permiten la deducción o producción de uno a partir de otro -sistema conjuntista-identitario-; en cambio, si tal conjunto de transformaciones determinadas no existe, los objetos son otros (Castoriadis, 1993).

La permanente obsesión de la unidad derivó en una filosofía que muestra el dominio ininterrumpido del sistema conjuntista-identitario y que podemos advertir en 
el camino de las razones que van desde el "todo debe ser dilucidado" -objetivo inalcanzable del pensamiento filosófico- a "todo debe ser organizado" y desde "se debe dar cuenta y razón de lo que se formula" a "todo debe ser fundamentado y a partir de un único fundamento" (Castoriadis, 1996b, p. 157).

Pero lo nuevo supondrá la posición de una forma que no es ni producible ni deducible a partir de otras formas, es decir, que refiere a la posición de nuevas leyes. La creación implica que las determinaciones que se aplican al ser nunca estén cerradas, de tal manera que inhiban el surgimiento de otras determinaciones. Esto es que la unidad del ser se halla fragmentada: ser y modo de ser no son separables y los modos de ser emergen, alterando por esto el ser mismo y manifestando el ser como autoalteración (Castoriadis, 1993).

Llevada al plano de la institución de la sociedad, la noción de alteridad de Castoriadis contiene una tensión entre la ausencia de sentido y la emergencia de lo nuevo. Explicitar la institución como el resultado de la autocreación supone que los individuos y las colectividades -frente a la repetición que promete el estado de clausura- asuman la alteridad en su radicalidad perpetua, la apertura ante la alteridad como sentido. En este caso la alteridad entraña la autodisolución y la autocreación.

Entonces, lo nuevo tendrá el carácter de la alteridad que nace en lo viejo subvirtiéndolo al hacerse explícito. Ello implica aceptar que el mundo -como autoconstrucción de la sociedad- es del orden de la irrupción de la alteridad que admite una ruptura radical, o sea que ese mundo conlleva la posibilidad de su destrucción como sentido (Miranda, 2010b).

\section{La búsqueda de la autonomía como proyecto}

Habíamos visto que en la organización endógena prevalece la clausura como significación y principio de la heteronomía. Cabe en este punto agregar la noción de que la presión de lo instituyente podrá dar cuenta de la alteridad negada u ocultada, al volver explícita esa violencia en el origen que supone asumir la autocreación de la forma, que adquiere la apertura de la clausura, y cuya condición de emergencia es compatible con la institución de la autonomía (Miranda Redondo, 2010b). Por eso, la autonomía es para Castoriadis la otra posibilidad para el posicionamiento del sujeto socializado, que surge cuando este es capaz de reflexionar y cuestionar sobre los fundamentos de sus significaciones. ${ }^{1}$

En cuanto a la autonomía de la colectividad, esta no puede realizarse más que a través de la autoinstitución y el autogobierno explícitos, siendo inconcebible sin la autonomía efectiva de los individuos que la componen. $Y$, a su vez, lo inverso es también cierto; no se puede ser libre bajo una ley si no se ha tenido la posibilidad de

\footnotetext{
${ }^{1}$ En la Grecia Antigua y en la Europa moderna la situación de heteronomía fue quebrada al producirse una ruptura en el cierre del sentido, expresada a través del cuestionamiento de las instituciones establecidas, mediante la política, y de las representaciones comúnmente aceptadas, mediante la filosofía (Castoriadis, 1995).
} 
participar en su formación y en su institución -incluso cuando las preferencias propias no hayan prevalecido.

Esta concepción de la autonomía aparece vinculada con la noción de praxis como actividad consciente que, apoyada en un saber siempre fragmentario y provisional, transforma al sujeto que la ejerce, volviendo a este en su propia acción y en su propia reflexión, como una experiencia transformadora.

Como dimensiones inseparables del conocer y el actuar humanos, autonomía y heteronomía se encuentran en permanente tensión. La institución social, en gran parte, puede crear un obstáculo infranqueable a la aspiración liberadora (Castoriadis, 2006a). Aunque las reivindicaciones de la libertad de pensar y actuar son permanentes, no están determinadas en la naturaleza humana, por ello, Castoriadis concebirá la búsqueda de autonomía como proyecto, como un trabajo por ser autónomo.

$Y$ en tanto proyecto, siempre expresa una tensión. Lo anticipatorio, lo que va prefigurándose, no se presenta en estado puro, ni es aislable, ni está cerrado en sí mismo, sino que se constituye en constante relación y contradicción con las formas sociales dominantes, en la disputa por cambiarlas y superarlas y ante las cuales lo alternativo lucha por no ser subordinado (Thwaites Rey, 2013).

En El Avance de la Insignificancia. Las Encrucijadas del Laberinto IV, publicado en 1996, hallamos un profundo análisis sobre la independización de lo funcional/instrumental, el repliegue de la creatividad, y la irracionalidad de plantear todo desde una perspectiva racional, proceso que ha ido acrecentándose coincidentemente con la hegemonía del imaginario capitalista de subordinación a la eficacia que impide inquirir sobre el sentido y destino de tal imposición (Castoriadis, 2007).

Pero, a la vez, esta clausura entraña la posibilidad de pensar-hacer la radicalidad política; así, los movimientos sociales y las revoluciones silenciosas -la de la mujer, la de las minorías, la de los colectivos autogestionados- empujan a mirar de nuevo la historia como un espacio de creación y de auto-creación.

De este modo, se nos presenta una encrucijada histórica. Una vía ya trazada es la del aumento del consumo, la repetición de formas vacías, el conformismo, la apatía, la irresponsabilidad y el cinismo, junto con la expansión de un control pseudo racional. Esta situación es interpretada por la ideología posmoderna, considerando al estancamiento y la regresión como expresiones de madurez, de un final de las ilusiones, y reivindicando el rechazo a la innovación, a la originalidad y a la coherencia de la forma. Castoriadis (1996b) visualiza este camino como el retorno de la heteronomía.

A su vez, la otra vía apuntaría a revivificar el proyecto de autonomía individual y colectiva surgido en la modernidad. Castoriadis ( $\mathrm{s} / \mathrm{f}$ ) sostiene que tenemos que ir más lejos que los modernos. El problema es el de instaurar una verdadera democracia en las condiciones contemporáneas, hacer de la universalización formal, incompleta, una 
universalidad sustancial y sustantiva. Con esto, está valorando a la democracia como régimen de autocreación colectiva y explícita de instituciones sociales, donde ninguna posición ni estatus están determinados o garantizados de partida, es un proyecto que permite la puesta al día del poder instituyente y su explicación reflexiva.

Es entendible que en las posibilidades que se vislumbran para este nuevo camino encontremos nuevamente la tensión heteronomía-autonomía, al tener que responder a dos desafíos: uno es cómo enfrentar la institucionalización de las prácticas adquiridas en las luchas ante la pretensión del poder dominante de reencauzar su fuerza disruptiva en la propia lógica; y otro es cómo extender la experiencia autónoma más allá del espacio en que se desarrolla para que sea una alternativa a las relaciones sociales mercantilizadas (Thwaites Rey,2013).

\section{El rol de la academia ante el avance de la insignificancia}

La fuerza de la razón, la libertad, la igualdad, la ley, el cuestionamiento indefinido, la democracia, y la expansión ilimitada del dominio técnico, en tanto significaciones imaginarias de la modernidad, portan una contradicción insalvable. La duda sobre la posibilidad y el valor de lo establecido implica instituciones flexibles y críticas, que -a la larga- no pueden convivir con la dominación técnica excluyente que conduce a la escisión burocrática entre dirigentes y ejecutantes, la explotación económica y el totalitarismo.

La prolongada contaminación mutua entre el proyecto de autonomía y el proyecto de expansión y dominación ilimitada ha llevado a la desintegración de los factores de vinculación social, en la ineptitud de las instituciones para generar individuos que sean capaces de hacerlas funcionar y reproducirlas (Castoriadis, 1996a).

Este pensamiento es central en la discusión sobre la modernidad en el último tramo del siglo pasado. Así, en la concepción posmoderna de Lyotard (1991) la cohesión social sería solo una intención perteneciente al relato unificador de la modernidad -en el supuesto de poder construir consenso en base a acuerdos de sujetos libres y por medio del diálogo-, que no puede hacer frente a los localismos, discontinuidades, disgregaciones y disensos que conforman la realidad efectiva. Desde un razonamiento opuesto, Habermas (1993) verá con preocupación la penetración de una forma de modernización regida por estándares de racionalidad instrumental en las esferas de la acción comunicativa -centrada en la integración social y la socialización. Esto genera una práctica cotidiana reificada que únicamente podrá modificarse por la creación de una interacción libre de presiones de los elementos cognitivos, morales, prácticos y estético-expresivos. Se trata, entonces, de revincular a la cultura moderna con el mundo de la vida, con instituciones que pongan límites a la dinámica interna y a los imperativos de un sistema económico casi autónomo.

Esa racionalidad instrumental cuestionada por Habermas, y a la que Castoriadis alude como pseudo-racionalidad, incluye a la ciencia, en la medida en que la vigencia 
forzosa del principio de eficacia legitima prácticas relacionadas con la creación, transmisión y aplicación del conocimiento científico independientemente de cualquier cuestionamiento acerca de qué se investiga, a quiénes beneficia, qué costos tiene, qué fines persigue, y cómo se forma a los estudiantes (Miranda Redondo, 2011; Díaz, 2007).

Bajo estas condiciones, nos surge la pregunta acerca de la manera en que está operando la universidad en sus funciones de generación y transferencia de conocimientos, en la reproducción y repetición de la sociedad.

Una respuesta es la ofrecida por Javier Maisterrena al afirmar que en la universidad latinoamericana actual funcionan dos medios de socialización que autosometen, fracturan y atomizan a investigadores y docentes al interior de sus instituciones: el poder y el dinero.

En su análisis de colectivos académicos, grupos, redes y asociaciones interinstitucionales cuyo objetivo es discutir sobre problemáticas de estudio y, en ocasiones, las propias prácticas, sostiene que el interés primordial en estos espacios parece concentrarse en la producción y la productividad exigidas para la sobrevivencia individual y en un ascenso en el prestigio académico. De esta manera se reproduce la heteronomía en el campo del conocimiento, cumpliendo con los roles asignados para que el gobierno y el capital repitan la sociedad al infinito con fundamento científico (Maisterrena Zubirán, 2013).

El papel de la universidad en la sociedad heterónoma ha sido analizado también por Claudio Albertani (2013). El autor repasa los procesos de cambio ocurridos desde la academia tradicional a la universidad-empresa, o capitalismo académico, de nuestros días (Albertani, 2013). El recorrido por el siglo veinte muestra el pasaje de la universidad moderna a la universidad masa. Si bien esta última constituyó un mecanismo de movilidad social, al mismo tiempo se convierte en un intento por encapsular el potencial transformador de las luchas de generaciones de trabajadores que le dieron origen.

En el presente ha cobrado fuerza la teoría del capital humano que, al equiparar la posesión de bienes educativos con cualquier otra inversión económica, condiciona a formar funcionarios tanto del capital como del Estado o de la universidad misma, imponiendo una educación evaluada con criterios cuantitativos — ranking, calidad total, eficiencia terminal, excelencia académica - que ha transformado al conocimiento, a los saberes básicos y a los investigadores en un apéndice del mercado.

En sintonía con Albertani, Maisterrena (2013) sugiere ciertas preguntas que se plantearían los centros de educación superior -y que son exigencia de la instancia certificadora de universidades e institutos de investigación-, tales como ¿cuál es el mercado de trabajo para los egresados? ¿Qué saben hacer que sea vendible? ¿Qué demanda el mercado de bienes? ¿Acaso no es el mercado quien define la noción de innovación? 
La universidad funcionaría como lugar de producción, organización y jerarquización de la fuerza de trabajo, integrando redes de cooperación que son combinaciones conflictivas de autonomía y mando capitalista, de lucha social y de control desde arriba. Esta realidad se asemeja a lo anticipado por Adorno con respecto a la docilidad a las exigencias del poder producto de la enajenación de lo humano (Albertani, 2013). ${ }^{2}$

La posibilidad de avanzar en la comprensión de los puntos de tensión existentes entre el ejercicio de la autonomía y la condición de docente y/o investigador aportará a un ineludible debate sobre la sociedad democrática y el resurgimiento del poder instituyente.

\section{Pensando con y sobre la ciencia social}

La autonomía como proyecto, en tanto entraña la posibilidad de relacionarse con otro autónomo y consigo mismo como otro y llegar a acuerdos con el otro para autonormarse, exige la decisión creativa del sujeto y el colectivo que participan en el desafío. Desde esta perspectiva se presenta la oportunidad de interrogarnos acerca de qué se espera de la ciencia social en el camino hacia la búsqueda de autonomía.

Para responder, hacemos entrar en escena, en primer lugar, las ideas de Castoriadis sobre cultura y poder Este autor concebirá a la cultura en tanto dominio del imaginario en el sentido estricto, el dominio poiético, que llega más allá de lo meramente instrumental. $Y$ en cuanto al poder, admitirá que toda sociedad instituye un poder explícito, al que liga la noción de lo político. Pero reconocerá en el imaginario colectivo anónimo la existencia, al mismo tiempo, de un poder instituyente -creador de las significaciones imaginarias sociales- que nunca puede ser completamente explicitado. ${ }^{3}$

Desestimando cualquier determinismo en lo social, al considerar la relación de cada sociedad frente a su institución, Castoriadis afirma que el hacer-pensando la institución es el momento de la complejidad y del rebase de la determinidad (Castoriadis, 1995, 2007). Llegado a este punto surgen un par de cuestiones a plantear en nuestra práctica investigativa ¿estamos predispuestos para comprender el otro lugar de la humanidad desde una posición que no sea el de las categorías propias? Y ¿podemos, efectivamente, evitar contemplar el proceso de acción de los otros como observadores

\footnotetext{
${ }^{2}$ En las reflexiones de estos autores latinoamericanos encontramos huellas del pensamiento de Lyotard sobre la función atribuida a la enseñanza para intentar alcanzar la mejor performatividad del sistema social con el objetivo de contribuir a la conservación de su cohesión, considerando que en la sociedad de la información las universidades no están destinadas a formar una élite que guíe a la nación hacia su emancipación -ilusión de la modernidad-, lo que se refleja en el pasaje de la pregunta sobre el conocimiento de ¿qué es verdad? a ¿para qué sirve? (Lyotard, 1991).

${ }^{3}$ Castoriadis (2006b) disentirá tanto con Hegel como con Marx por considerar que obviaron la distinción entre la cultura, en el sentido estricto del término, y la dimensión puramente funcional de la vida social. Asimismo cuestionará a Max Weber por haber identificado la dominación legal/racional con la democracia, régimen en el cual el poder supone ejercicio del dominio que implica la interiorización de la norma.
} 
ajenos y asépticos; o de verlo exclusivamente como algo dado, en una linealidad pasado-presente?

Entendemos que ello es factible en la medida que se asuma que estamos aquí como cientistas sociales no para decir lo que es, sino lo que no es, y que en la formulación de las predicciones e hipótesis se tomen en cuenta los múltiples tiempos, las certezas parciales y las bifurcaciones que acontecen en el campo social-histórico.

\section{Nuevos desafíos para las ciencias sociales en ALyC}

Acordamos entonces que, ante lo indeterminado, el conocimiento implica decidirse por opciones diversas y tomar acción; el objetivo es detenernos en el qué y el para qué de ese conocimiento, poder ir más allá de la representación de campos acotados por la institución y la compartimentalización de los saberes, rearticulando el conocer, el decir y el actuar (López Segrera, 2000; Scribano, 2009).

Para Castoriadis (1995) el agotamiento de significaciones y prácticas de los proyectos emancipatorios, tanto revolucionarios como progresistas, abrió la alternativa de pensar-hacer la radicalidad política. En el caso de América latina, durante la posguerra y luego en la década de 1970, las organizaciones que intentaron la toma del poder, la imaginaron con mecanismos que repetían la producción heteronómica de los países centrales. Por su parte, los partidos políticos y sindicatos reiteraron prácticas basadas en la heteronomía y burocratización, con el correlato de la desvinculación entre dirigidos y dirigentes, lo que condujo a que fueran fuertemente cuestionados (Heras, 2009).

En el último tramo del siglo veinte la crisis provocada por el aumento de la conflictividad a partir de las modificaciones tecnológicas del proceso productivo y las modalidades de valorización del capital se plasmó en América Latina en dictaduras militares, globalización de los mercados y fin del estado de bienestar (Borón, 1993). Su correlato ha sido la producción de insignificancia en lo referente a las significaciones imaginarias sociales que suponen lo público, lo estatal. Presente como nunca en su racionalidad burocrática, el Estado trastocó sus funciones, vaciando las prácticas del bien común.

Como reacción a las políticas neoliberales se fueron gestando SIS que crean nuevas realidades en la acción política irrumpiendo en prácticas orientadas a proyectos de autonomía que "buscan la igualdad de palabra y poder de acción, la paridad en la toma de decisiones, y la franqueza como soporte de los discursos normativo y retórico dejando de lado los mecanismos pasados" (Heras, 2009, p. 98).

Los colectivos que se inventaron en Argentina como parte de aquella reacción "mantuvieron fuertes voluntades de autogestión, horizontalidad, democracia directa y autonomía en relación con las formas tradicionales de la política" (Fernández, 2007, p. 7). Sin embargo, esas acciones encontraron la incomprensión de gran parte de la inteligencia progresista "que no entiende este magma de acciones micropolíticas 
productoras de situaciones nuevas" (Fernández, 2007, p. 7). Estas prácticas se vuelven invisibles al no dárseles entidad porque no cumplen con las precisiones de modelos que, desgastados pero vigentes, operan como únicas categorías de entendimiento. Ello hace necesario poder discernir las lógicas con que actúan, magmáticamente, colectivos políticos que funcionan de un modo diferente a las formas históricas de luchas populares, e "inventar herramientas de pensamiento para leer aquello que, aunque no se manifieste en las acciones habituales y rutinarias, está en ebullición" (Fernández, 2007, p. 8).

\section{Imaginar-hacer transdisciplinariamente la complejidad}

Impensar y abrir las ciencias sociales latinoamericanas es una consigna que viene planteándose hace dos décadas. Ello implica sortear la distinción entre el método idiográfico y el nomotético, interpretando que "las ciencias sociales no deben ser ni un mero recuento de los hechos del pasado, ni la simple búsqueda de regularidades con una visión ahistórica" (López Segrera, 2000, p. 11) y, fundamentalmente, poder eliminar las barreras disciplinarias. Sobre la cuestión de esas barreras, Castoriadis aseveraba que:

La fractura del universo de la investigación y del pensamiento en disciplinas que no se comunican entre sí, donde cada una tiende a desarrollar un dogmatismo propio y a enceguecerse con respecto al resto, constituye un factor de decadencia e incluso de heteronomía pura. (Castoriadis, 1996b, p. 160)

A su vez, conteste con el pensamiento de Castoriadis, Miranda Redondo (2006, 2011) afirma que los intentos del determinismo filosófico, el positivismo y las leyes de la historia para reducir la complejidad, remitirían a una nostalgia de clausura, como forma de manifestarse, la repetición, opuesta a la alteridad que supone en la multiplicidad la posibilidad de ruptura y la emergencia de lo nuevo

Metodológicamente, el objeto complejo es aquel que puede ser aprehendido en múltiples estados de existencia, dado que opera en distintos niveles de la realidad, incorporando formas de determinación generadas por procesos aparentemente desordenados, caóticos.

Ante la producción y reconocimiento de objetos radicalmente nuevos, el antropocentrismo del cientista de raigambre cartesiana pierde relevancia: la no linealidad, las discontinuidades, los ruidos, las contradicciones y las paradojas manifiestan complejidades que demandan discursos que atraviesen disciplinas, compartiendo lenguajes y estructuras lógicas y simbólicas capaces de dar cuenta del objeto (Almeida, 2010).

Un caso de trasvasamiento disciplinar y emergencia de objetos de conocimiento lo constituye el giro operado en las ciencias cognitivas luego de que las estrategias computacionalistas que marcaron el desarrollo de aquel campo durante la segunda 
mitad del siglo pasado mostraron limitaciones insuperables. Esa crisis posibilitó que la atención de los investigadores cognitivos y los grandes centros tecnológicos recayese en las filosofías del conocimiento y las ciencias humanas (psicología del desarrollo, lingüística, psicoanálisis), con su bagaje de ideas sobre la subjetividad, y en investigaciones socioculturales y ambientales para enfrentar problemas provocados por la globalización de los mercados y el crecimiento de las redes informáticas interactivas (Samaja, 2007).

Otro ejemplo lo hallamos en los estudios culturales. Surgidos en Inglaterra y trasladados a Estados Unidos, desde los años 80 adquirieron fuerte presencia en las ciencias sociales latinoamericanas, expresada en autores como Néstor García Canclini, Renato Ortiz o Jesús Barbero, cuyos trabajos aportan una orientación superadora de los límites tradicionales entre las disciplinas sociales que les ha abierto puertas en los campos de la comunicología, la antropología, la filosofía, la literatura y el arte. ${ }^{4}$ Conceptos nucleares se constituyeron en problemas-objeto poniendo en juego el sentido mismo del término. Tal es el caso de la definición de lo popular donde la irrupción de lo masivo sumado a las nuevas tecnologías de los medios y las migraciones internas originaron nuevas significaciones: de atraso a encuentro de subjetividades emergentes y de negación a resistencia.

Un tercer ejemplo son los aportes latinoamericanos en que la psicología se ha vinculado con otras disciplinas del área de las ciencias sociales. Tal es el caso del método alfabetizador de Paulo Freire que articula la dimensión psicológica de la conciencia personal con su dimensión social y política, y pone de manifiesto la dialéctica histórica entre el saber y el hacer, el crecimiento individual y la organización comunitaria, la liberación personal y la transformación social (Martín-Baró, 1986).

Durante las últimas tres décadas conceptos claves que incluyen concientización, realismo crítico, desideologización, marco social, opción preferencial por las mayorías oprimidas y eclecticismo metodológico fueron incorporados por un nuevo campo transdisciplinar: la psicología social de la liberación (Burton, 2004).

Su aplicación se dirige a tres áreas: la psicología comunitaria, con énfasis en la transformación social y el uso de métodos participativos, incluyendo las subramas ambiental-comunitaria y clínica-comunitaria; el trabajo psicosocial con víctimas de la represión estatal, enfocado a nivel de la sociedad; y la psicología política (Rodríguez Kauth, 2001), que en sus análisis e interpretación de la realidad utiliza tanto conceptualizaciones psicosociales como políticas, históricas, ideológicas, filosóficas y económicas, integrando la información del entorno por el que se encuentra atravesada la subjetividad individual y colectiva.

\footnotetext{
${ }^{4}$ Cfr.: Jesús Martín Barbero (1998) De los Medios a las mediciones. Comunicación, cultura y hegemonía (5a ed.), Bogotá: Convenio Andrés Bello; Néstor García Canclini (1982) Las culturas populares en el capitalismo, México: Nueva Imagen; Renato Ortiz (1997), Mundialización y cultura. Buenos Aires: Alianza.
} 
La psicología social de la liberación estaría aportando una respuesta neoparadigmática a las necesidades de las sociedades latinoamericanas que permite rescatar el potencial de recursos que las personas tienen para lograr transformaciones, muchas veces invisibles para ellas debido a condiciones históricas, culturales y sociales. Esta nueva configuración reconoce influencias de la sociología militante o crítica de Fals Borda, la educación popular freiriana y su área de influencia que incluye a sociólogos, antropólogos y educadores tales como Vio Grossi y Le Boterf; la etnometodología, y algunas formas de antropología (Montero, 2004).

Por último, recurrimos a un caso más acotado, referido a una línea de investigaciónacción que se desarrolla en el marco de dos centros de Argentina, IRICE e INCLUIR, orientada al aprendizaje, la creación y la percepción de la diferencia en proyectos de autonomía (Heras, 2012). Su objetivo es construir como objeto de estudio a los aprendizajes distintivos de los proyectos de autonomía, sus traducciones a discursos y acciones de autogestión, y sus tensiones con respecto a la diversidad, la diferencia y el binomio igualdad-desigualdad. En estas investigaciones son consideradas clave la noción de acción política de Arendt, las contribuciones de Castoriadis y Guattari sobre la autonomía y el poder, porque han cruzado fronteras discutiendo sus vertientes disciplinares para responder interrogantes ubicados en puntos de sutura entre campos que algunas disciplinas han escindido, tales como psique y sociedad; subjetividad y racionalidad; razón y creación (Heras, 2009).

\section{Significados, limitaciones, modalidades y proyecciones de la transdisciplina}

En la literatura sobre el tema, el término transdisciplina alude al vínculo que une orgánicamente aspectos de diversas disciplinas en relación con un objeto emergente no abarcado por ninguna de ellas; vinculación problemática, según Follari, ya que se establece entre campos inconmensurables "porque la tendencia de los discursos disciplinares no es la confluencia natural ni la coherencia mutua" (Follari, 2001, p. 42).

Naomar Almeida considera que la actividad transdisciplinaria debe proponer una familia de objetos científicos simultáneamente fronterizos, mestizos y complejos, los transobjetos. Considerando que cada vez más la producción del conocimiento científico será social, político, institucional, matricial, amplificado, el trabajo de la ciencia deberá hacer viables síntesis transdisciplinarias, aunque parciales y provisorias, de los objetos de la complejidad (Almeida, 2010). Esta nueva forma transdisciplinaria fundaría una relación con el otro por la alteridad que corresponde a la dimensión imaginaria, del orden de la creación.

Como modo de considerar las implicaciones transdisciplinares, Vega Torres propone asumir la alteridad de los estilos narrativos en las ciencias sociales, pensando su saber como un diálogo de posiciones que contribuyen a significar y resignificar lo histórico social de modo que se vuelva a lo que lo constituye propiamente: la narración. 
En la forma narrativa converge la producción de saberes en un trabajo sociológico, antropológico, lingüístico e histórico; en la medida en que se aplica en profundidad sobre un problema, las fronteras entre las ciencias se borran (Vega Torres, 2012).

Oliver Costilla (2008) refiere a la presencia de la transdisciplina en el campo de las ciencias sociales a través del pensamiento crítico latinoamericano, iniciado con el ensayismo de finales del siglo diecinueve y comienzos del veinte y que en los años 1980 y 1990 polemizará con el pensamiento estadounidense. Actualmente el diálogo entre disciplinas "se afirma en los movimientos sociales y en los espacios académicos como eje en la construcción y discusión de ideas donde se desvanecen fronteras del saber y crean aportes teóricos que pertenecen a/y propician un conocimiento abierto en sus parámetros de producción de conocimiento y observación de la realidad" (Oliver Costilla, 2008, p. 130).

No obstante, la posibilidad de que esas prácticas creen cambios en el poder académico institucional ha sido puesta en duda por Follari, por considerar que "la ocupación simultánea de varios espacios disciplinares y departamentales o la ubicación privilegiada en estudios o programas transdisciplinarios no entraña que el poder institucional se haya diluido, sino que se trataría de una nueva forma de ejercerlo" (Follari, 2001, p. 41).

En este caso, si consideramos al discurso y la posición académicas como prácticas heterónomas, el mantenimiento de la estructura de poder -al que refiere Follari- se correspondería con la negación de la dimensión instituyente de la sociedad, el recubrimiento del imaginario instituyente por el imaginario instituido unido a la conformidad de individuos que (se) viven y piensan en la repetición. Más allá de la intención integradora de conocimientos, permanecería la diversidad correspondiente al plano conjunto-identitario, de la repetición a partir de lo mismo. En última instancia, la tradición significa que la cuestión de su legitimidad no será planteada.

Pero, si traspasar barreras disciplinarias constituyese un quiebre del sentido, entonces ello entrañará una actividad de interrogación y el rechazo de toda autoridad que no justifique la validez del derecho de sus enunciados, de una fuente de sentido diferente a la actividad viva de los sujetos concretos.

Al interpretar la introducción de enfoques transdisciplinarios en la academia en el marco de procesos de creación/destrucción/emergencia radical (Miranda Redondo, 2010a), podemos mirar la situación desde una perspectiva distinta a la presentada por Follari. En ese caso, en una organización donde se pueda tomar distancia con respecto a lo instituido, dicha incorporación implicaría de parte de los investigadores su aceptación de la alteridad como ocurrencia de lo nuevo.

En esa circunstancia, con la alteración del estado de repetición y clausura que suponen los fundamentos ontológicos, los criterios epistemológicos y las reglas metodológicas como metanorma de la disciplina original, la introducción de un tercero -otros conocimientos y prácticas- se asumiría necesariamente un espacio de relación 
distinta entre institución -en tanto poder explícito- e instituyente -en la negación del refugio disciplinar.

El proceso de construcción transdisciplinar pondrá en juego la capacidad de los investigadores académicos para admitir que en la medida en que la creación de sentido es posible, lo es también su total destrucción, o sea que al igual que toda norma instituida, los conocimientos y los métodos establecidos también son perecederos.

Esta segunda perspectiva implica la oportunidad de desarrollar una producción libre y creativa entre cientistas de distintas disciplinas realizando una elección explícita por la autonomía que, en tanto proyecto inacabado, se hace posible con el compromiso y una forma diferente de investigar y de relacionarse con el otro. Somos conscientes de la dificultad para lograr acuerdos en un campo formado por diversos juegos de lenguaje. En este punto se podría considerar la recomendación de Lyotard (1991) sobre la factibilidad de construir consensos locales y limitados en el espacio y en el tiempo.

Pero, fundamentalmente, coincidimos con Maisterrena Zurbarán (2013) en que, en el campo académico, el margen de apertura permitido de poder cuestionar todo, constituye un espacio válido para ir sentando condiciones que agrieten el cierre del sentido de la sociedad heterónoma y repetitiva colonial capitalista.

\section{Pluralidad de seres y sentidos: bases de las epistemologías del desprendimiento}

El romanticismo del siglo diecinueve puso en cuestión las separaciones fundamentales -natural y sobrenatural, sujeto y objeto, ritual/espiritualidad y tecnología/ciencia, secular y sagrado, público y privado, individuo y sociedad- que cimentaron la ciencia moderna y el reinado de la fe en la razón, planteando la urgencia de retomar la unidad entre humanidad y mundo, entre arte y naturaleza, entre filosofía y poesía. El postulado de la verdad por correspondencia con el objeto fue debilitándose durante el siglo pasado, prevaleciendo la mirada sobre "el sentido que es constitutivo del sujeto y hace que el mundo se torne comprensible, mostrando el entrecruzamiento de entes y razón, de deseo y signos en la multiplicidad de fuerzas que intervienen en la existencia" (Díaz, 2007, 64).

Nos referimos a (que) un saber (que) no se reduce a la ciencia ni al conocimiento; abarca el saber-hacer, saber-vivir, saber-escuchar, excediendo el criterio de verdad al asimilar otros como los de eficiencia, justicia, belleza sonora, cromática, etc. El consenso que permite circunscribir este saber y delimitar al que sabe y al que no sabe, constituye la cultura de un pueblo y en él prevalece lo que Lyotard denomina forma narrativa, donde se ponen en juego las relaciones de la comunidad consigo misma y con su entorno. Esta cultura no tiene necesidad de apoyarse únicamente en el pasado, el pueblo actualiza los relatos al contarlos, escucharlos y al interpretarlos en sus instituciones.

Pero el saber científico pregunta por la validez de lo narrativo y constata que no fue sometido a la argumentación ni a la administración de pruebas. Por tanto, lo define 
como salvaje, primitivo, subdesarrollado, atrasado, alienado, ignorante, etc. Esta relación desigual constituye toda la historia del imperialismo cultural de occidente (Lyotard, 1991). ${ }^{5}$

Precisamente, poder desobedecer los relatos canónicos desplegados por la matriz ético-política de la modernidad, imaginar una salida de la circularidad de la (pseudo) racionalidad, remite a la construcción de una crítica que logre el desprendimiento de las teorías tradicionales modernas y de las teorías críticas postmodernas conducentes a un paradigma-otro, no eurocentrado y pluriversal (Mignolo, 2010).

En el intento de encontrar pistas performativas del universo político-social latinoamericano se vienen generando constructos conceptuales claves. Tal es el caso de nociones como formación social abigarrada, creolización, traducción, altermodernidad, hibridación, decolonialidad, e imaginario social de la naturaleza y la sustentabilidad.

Introducido por René Zavaleta Mercado, el concepto de formación social abigarrada describe una sociedad donde se yuxtaponen en relaciones asimétricas distintas culturas y sus modos de producción: "territorios que reinventan las figuras del hacer colectivo, situaciones complejas y singulares cuya evidencia son los desplazamientos que atraviesan todo tipo de fronteras, países, oficios, costumbres, lenguajes, comidas, etc." (Rivera Cusicanqui, 2010, p. 70). Rivera plantea la necesidad de una economía política del conocimiento que desmenuce las estrategias económicas que operan detrás de los discursos. El pensamiento descolonizador parte de la afirmación del nosotros bilingüe, abigarrado, proyectado como cultura, teoría, epistemología, política de Estado y definición nueva del bienestar y el desarrollo. El desafío es construir lazos sur-sur que rompan los triángulos sin base de la política y la academia del norte.

Otro concepto que consideramos aquí es el de creolización. Edward Glissant aduce que el mundo como relación -en lugar del mundo como imposición y soledadresponde a un pensamiento de archipiélago, abierto al cambio, a múltiples posibilidades combinatorias que impiden solidificar construcciones identitarias en la región caribeña, cuya constante es la mutación, la fragilidad, la inestabilidad. Glissant propone la creolización del mundo valiéndose de conceptos como la identidad rizoma ${ }^{6}$ -que destruye el principio de filiación sobre el cual se apoya la legitimación del poder-, el imaginario como construcción simbólica mediante la cual una comunidad se define a sí misma, y la poética de la relación -en tanto alternativa de los pueblos para renunciar

\footnotetext{
${ }^{5}$ Castoriadis habla del rechazo del otro en tanto que otro: "Ingrediente no necesario pero sí probable en grado extremo de la institución de la sociedad. Natural -en el sentido en que la heteronomía de la sociedad es natural. Superar ese rechazo exige una creación a contracorriente, lo que la vuelve improbable" (Cornelius Castoriadis, 1987. Reflexiones sobre el racismo. En Estudios, filosofía / historia / letras No. 9. México: Instituto Tecnológico Autónomo de México. Recuperado el 20 de noviembre de 2014 de http://biblioteca.itam.mx/estudios/estudio/estudio09/sec_3.html).

${ }^{6}$ Un rizoma reviste diversas formas: expansión de sus entramados en todas las direcciones en la superficie, nudos de condensación en sus bulbos, etc.; análogamente se utiliza el término en referencia a la realidad rizoma, configurada por un movimiento transversal que impide establecer una relación localizable y unidireccional entre las cosas.
} 
a la espiritualidad, la mentalidad y el imaginario estimulados por una concepción identitaria de la raíz única- (Boidin, 2008).

También encontramos el concepto de traducción, que remite a la teoría de $\mathrm{H}$. Bhabha sobre la traducción cultural. Como translación entre tradiciones, individuos y lenguas, Bhabha considera el tercer término, el elemento indecidible (ni europeo, ni indio, ni negro ni blanco) que niega el discurso del colonialismo provocando una crisis para cualquier sistema de autoridad (Bhabha, 2002).

Otra noción considerada aquí es la de altermodernidad, incorporada por Nicolas Bourriaud proponiéndola como superación de dos cosmovisiones enfrentadas: modernismo y posmodernismo. El modernismo elogió desde su inicio la raíz: fue radical. Frente a ese modelo, hoy prevalece lo radicante, poner en escena las propias raíces en contextos y formatos heterogéneos a través de múltiples arraigos simultáneos y sucesivos: intercambiar en vez de imponer, como modo de relacionar la cultura de la globalización y las culturas locales (Herrera, 2010). Se trata de promover la reescritura de la historia oficial en beneficio de relatos plurales, permitiendo la posibilidad de dialogar entre versiones diferentes, evitando la extensión de la uniformización cultural.

El concepto de hibridación propuesto por García Canclini (1989) pretende traspasar las relaciones de oposición entre lo popular, lo culto y lo masivo, lo lúdico y lo racional, lo mítico y lo tecnológico, lo objetivo y lo subjetivo, lo tradicional y lo moderno, al reconocer en la base de los movimientos de reorganización cultural típicos de la modernidad tardía y del propio sentido de la modernización la marca de una creciente ruptura de las demarcaciones rígidas, ontológicamente constituidas por los fenómenos y procesos socioculturales modernos.

Se trata de procesos de desterritorialización que harían posible la convivencia simultánea de distintas temporalidades históricas en un mismo espacio social, que en América Latina acontecen de manera radicalizada y distinta a los patrones institucionales imaginados por las sociedades de la Europa iluminista.

Esto da lugar para pensar en un proyecto donde los lugares de producción de nuevos sentidos se descentralicen, permitiendo una inversión en la redefinición de las instituciones y espacios modernos, ${ }^{7}$ admitiendo la posibilidad de que la modernidad sea un proceso orientado por la propia pluralidad del orden social, que gana voz solamente en un contexto de reflexividad $y$, como consecuencia, genera una multiplicidad de posibilidades de ser moderno (Retondar, 2008).

Otro de los conceptos que tomamos es el de decolonialidad, constructo que entraña el cuestionamiento radical del carácter homogeneizante de la episteme política colonial

\footnotetext{
7 Véase también: Shmuel Einsenstadt (2013), Las primeras múltiples modernidades: identidades colectivas, esferas públicas y orden político en las Américas. Revista Mexicana de Ciencias Políticas y Sociales, vol. LVIII, 218, 129-151. México D.F.: UNAM.
} 
de la modernidad y la posmodernidad, en un proceso de descolonización intelectual que busca contribuir a la descolonización ética, económica y política. ${ }^{8}$

Este giro decolonial constituye su posicionamiento en la perspectiva geopolítica del conocimiento. Nociones como colonialidad del poder e interculturalidad abren las puertas de conocimientos que fueron subalternizados en nombre de las cosmovisiones occidentales, revelando y poniendo en juego la diferencia colonial en demanda de un pensamiento crítico, presente en las ideas de Dussel, Quijano, Mignolo, Lander, Escobar, Walsh, De Sousa Santos, entre otros.

En la alteración de los conceptos centrales y constitutivos del relato de la modernidad que encara la epistemología decolonial se harán presentes dos de las ideas fuertes del pensamiento de Castoriadis. Una es la referida a la tensión entre las dos significaciones imaginarias sociales de la razón que, según Castoriadis, ${ }^{9}$ dejaría trunco al proyecto moderno desde sus orígenes -la promoción de la autonomía (la razón para ser libres, decidir la forma en que queremos vivir), y la expansión ilimitada del dominio técnico (la razón como instrumento para el uso del mundo). Y la otra es la ya mencionada tensión entre la ausencia de sentido y la emergencia de lo nuevo que entraña la noción de alteridad (Miranda Redondo, 2010b).

Walter Mignolo (2010) distingue entre el concepto de colonialismo surgido con la conquista de América y el de colonialidad, que emerge como un nuevo patrón de dominación social. En sus análisis reconoce los aportes de Michel Foucault a través del concepto de biopolítica y de Frantz Fanon cuyas ideas sobre la descolonización integran al cuerpo, anteriormente desprestigiado y eludido tanto por la teología cristiana como por el pensamiento cartesiano.

Mignolo define la creación de la modernidad como fenómeno europeo constituido en una relación dialéctica con una alteridad no-europea. Desde dicha relación, el autor da cuenta de la naturaleza de una modernidad construida, que se ha enmarcado desde sus comienzos dentro de principios como el de racionalidad y emancipación, concepto este último que, perteneciendo a la Ilustración, actualmente sigue siendo utilizado dentro de la misma tradición del siglo XVIII. Esto lleva al rechazo de esa noción por parte de Mignolo y su sustitución por el concepto de liberación, entendiendo que la conversión de la teoría crítica en crítica descolonial deriva en un pensamiento crítico de frontera a través del cual el vuelco epistémico decolonial (la descolonización del saber y del ser) marca los límites eurocéntricos de la teoría crítica tal como la conocemos hoy.

Aníbal Quijano (2000) rebatirá la visión dualista de la historia atribuyéndole los mismos problemas que, como vimos más arriba, plantea Castoriadis: no encontrar la

\footnotetext{
${ }^{8}$ Ese cuestionamiento podría reconocer afinidad con el pensamiento de Lyotard (1991) cuando advierte sobre la similitud entre el tipo de lenguaje científico y el de la ética y la política al pertenecer ambos a la tradición de la razón occidental para concluir que en la modernidad el derecho a decidir lo que es verdadero se entrelaza con el derecho a decidir lo que es justo. De esta forma, saber y poder son las dos caras de una misma moneda.

${ }^{9}$ Ver R. Miranda Redondo, 2010a.
} 
manera de resolver la cuestión de la totalidad, negándola, como el empirismo o el posmodernismo, o entendiéndola solo de modo organicista o sistémico (o modo conjuntista-ensídico, en la terminología de Castoriadis). En los países colonizados el resultado es la heteronomía, producto de haber sido conducidos a ver y aceptar como nuestra y perteneciente a nosotros solamente la imagen construida por la perspectiva eurocéntrica. De esa manera seguimos siendo lo que no somos, lo que dificulta la identificación de nuestros verdaderos problemas y su resolución, a no ser de una manera parcial y distorsionada.

La tensión autonomía-heteronomía puede verse en los análisis sobre los conflictos entre la racionalidad económica y la racionalidad ecológica de Arturo Escobar (1999). Las economías comunitarias de América Latina y el Caribe incluyen el reconocimiento de bienes comunes compuestos de tierras, recursos materiales, conocimientos, ancestros, espíritus. La naturaleza no es algo externo, está arraigada en la práctica colectiva de seres humanos que se sienten conectados con ella en forma integral. En esa concepción, la visión reduccionista de la biodiversidad en términos de recursos genéticos que deben ser protegidos mediante derechos de propiedad intelectual, resulta insostenible.

Finalmente, mencionamos el imaginario social de la naturaleza y la sustentabilidad. Concebido por Enrique Leff (2010) como aquel donde sedimentan los principios de la vida generados fuera de las vías de socialización institucionalizadas que han incorporado al imaginario social el modo de pensar y de producir el mundo por una racionalidad económica anti natura.

Siguiendo la concepción de Castoriadis sobre las SIS, Leff (2010, p. 92) afirma que el imaginario social de la sustentabilidad se constituiría como un potencial de creatividad y alteridad en la construcción de sociedades sustentables. $Y$, en tal sentido, es una herramienta de reivindicación de culturas acalladas e invisibilizadas por el imaginario de la racionalidad económica, al mismo tiempo que se plantea como una búsqueda de alternativas que pongan en juego el diálogo de saberes como estrategia política para construir "el bien común y la sustentabilidad planetaria" (Leff, 2010, p. 98).

Este repaso de los nuevos constructos es una sucinta e incompleta muestra de los esfuerzos de las ciencias sociales de nuestra región por superar la mirada de lo histórico-social en base a enfoques deterministas/progresistas, ya sea que se trate de Kant, de Hegel o de Marx. Poder desarrollar una agenda de investigación que afronte autónoma e integralmente los problemas sociales involucra la construcción y discusión de conceptos, el dialogo crítico, la colegialidad y la confianza, coordinando acciones dirigidas a crear condiciones para que los sujetos mismos -los otros y los propios investigadores como otros- sean creadores de un futuro en libertad.

Maisterrena afirma que al conocer con el otro, se agregará la asociación de la práctica con lo que puede ser -e incluso lo que no ha podido ser- y no ha sido y solo será posible con la acción colectiva y autónoma que cree realidades, desplegando la 
capacidad de conocer-haciendo, de hacer futuros y ser corresponsable de crear sociedad autónoma con los otros -también autónomos- con quienes se articula. $Y$ sobre todo, posibilita la capacidad de autoalterarse individual y colectivamente, en un compromiso al que el sujeto de conocimiento se inscribe en toda su corporeidad (Maisterrena Zubirán, 2013).

La propensión hacia la individualización atomizante controlada desde afuera y determinada por el capital o el Estado, la sociedad de repetición, el confort provisto por la certidumbre dada por la heteronomía, según Maisterrena, oculta, evade o mitiga la propia responsabilidad creadora transferida a una figura imaginaria externa, como puede ser la ciencia reconocida por la academia heterónoma (Maisterrena Zubirán, 2013).

Deconstruir barreras disciplinarias requiere una definición pragmática de la transdisciplinariedad como proceso, estrategia de acción y modalidad de práctica. Ello no implica renunciar a la especialización de cada disciplina, sino ampliarla en función de la potencialidad de la práctica transdisciplinar para que contribuya a superar la fragmentación del conocimiento y proponga análisis exhaustivos.

Es ese marco el que tiene presente López Segrera cuando confiere a la transdisciplinariedad un papel crucial al aceptar los otros discursos, pensarlos críticamente y para construir un pensamiento ampliado eliminando fronteras entre sociología, historia, economía, derecho... y, fundamentalmente, entre las ciencias exactas y naturales, las ciencias sociales y el arte. $Y$ también Almeida, al plantear la necesidad de transformación radical del sistema de formación de los sujetos de la ciencia, capaz de construir síntesis y operar tránsitos entre los saberes de la vida y de la ciencia.

\section{Repensar las disciplinas ante realidades otras y saberes alternativos: conclusión abierta}

En este artículo hemos reflexionado sobre la creatividad de la historia, reconociendo el origen de otros mundos posibles construidos en el cuestionamiento al sistema social o al propio sistema de pensamiento, y entendiendo, en consecuencia, que tal reconocimiento implica para toda lucha política el requerimiento de ver tanto las dominaciones como las posibilidades inimaginables desde otro lugar (Castoriadis, s/f; Miranda Redondo, 2011).

Y pudimos advertir que los nuevos constructos conceptuales que dan cuenta de las singularidades del universo político-social latinoamericano conformando una epistemología del desprendimiento, no niegan todas las categorías de conocimiento de la modernidad, lo que evita el riesgo de disolver la realidad en el discurso.

Se trata entonces, fundamentalmente, de realizar una crítica política en la que se hacen-piensan modos de convivencia que puedan restituir a los agentes locales espacios de interrogación y creatividad; por lo tanto es acción, vinculada con las luchas 
concretas de colectivos sociales colonizados y subalternos (Mignolo, 2010, Mejía Navarrete, 2009). En el campo político latinoamericano van surgiendo en la última década algunos de estos espacios de incentivación de la politización popular, expresada en instancias de movilización y participación y articulada con la búsqueda de una integración ético-política entre los Estados orientada a encarar los asuntos regionales desde ámbitos progresivamente autónomos de la hegemonía norteamericana, que desempeñan un papel clave para afianzar la legitimidad democrática.

A lo largo de estas páginas fue tomando cuerpo la idea del ser como creación y destrucción, permitiéndonos comprender que aunque estemos condicionados por el pasado, nadie aseguró que ese pasado era necesario y que el proyecto de autonomía inicia una trayectoria basada en la posibilidad de ser de aquello que aún no ha sido pero puede ser. Sin dudas, ese pensamiento suscita una incertidumbre que, en parte, inhibe el salto para volverlo posible. Por ello, concluyendo, acordamos con Maisterrena (2013) que como cientistas sociales aquel paso existencial debemos realizarlo acompañados por otros que solidariamente permitan ver lo que uno pueda no ver. De esta forma, desde la academia, contribuiremos a ampliar la mirada de horizontes entre disciplinas distintas y colectivos sociales diferentes, entre estudiantes y formadores, entre investigadores y comunidades.

\section{Bibliografía}

Albertani, Claudio (2013). Pienso luego estorbo. Textos en defensa de la Universidad Autónoma de la Ciudad de México ( $2^{\mathrm{a}}$ ed.), México: Juan Pablos Editor.

Bhabha, Homi (2002). El lugar de la cultura, Buenos Aires: Ediciones Manantial.

Castoriadis, Cornelius (1993). Tiempo y creación. El Mundo Fragmentado. Encrucijadas del laberinto III (135-161). Buenos Aires: Editorial Altamira.

------- (1996a). El avance de la insignificancia. Buenos Aires: EUDEBA

--12007). La institución imaginaria de la sociedad. Buenos Aires: Tusquets.

Díaz, Esther (2007). Entre la tecnociencia y el deseo. La construcción de una epistemología ampliada, Buenos Aires: Biblos.

Fernández, Ana (2007). Lógicas colectivas, subjetividad y política. En Yago Franco, Héctor Freire y Miguel Loreti (Coords.) Insignificancia y autonomía. Debates a partir de Cornelius Castoriadis, cap. II. "La autonomía y el avance de la insignificancia", Buenos Aires: Biblos.

García Canclini, Néstor (1989). Culturas híbridas. Estrategias para entrar y salir de la modernidad. México: Grijalbo.

Habermas, Jürgen (1993). Modernidad, un proyecto incompleto. En Casullo, Nicolás (comp. ) El debate modernidad posmodernidad. Buenos Aires: El Cielo por Asalto. 
López Segrera, Francisco (2000). Abrir, impensar, y redimensionar las ciencias sociales de América Latina y el Caribe ¿Es posible una ciencia social no eurocéntrica en nuestra región? En Edgardo Lander (comp. ) La colonialidad del saber: eurocentrismo y ciencias sociales. Perspectivas Latinoamericanas, Buenos Aires: CLACSO.

Lyotard, Jean-François (1991). La condición postmoderna. Informe sobre el saber. Buenos Aires: Editorial R.E.I. Argentina.

Mejía Navarrete, Julio (2009). Semblanza de Aníbal Quijano. En J. Mejía Navarrete (ed.) Sociedad, cultura y cambio en América Latina (29-34), Lima: Universidad Ricardo Palma.

Mignolo, Walter (2010). Desobediencia Epistémica. Retórica de la modernidad, lógica de la colonialidad, gramática de la descolonialidad. Buenos Aires: Ediciones del Signo. Miranda Redondo, Rafael (2010b). La noción de alteridad en Cornelius Castoriadis. Madrid: Facultad de Filosofía, Universidad Complutense.

Quijano, Aníbal (2000). Colonialidad del poder, eurocentrismo y América Latina. En Edgardo Lander (comp. ) La colonialidad del saber: eurocentrismo y ciencias sociales. Perspectivas Latinoamericanas. Buenos Aires: CLACSO.

Rey, Mabel Thwaites (2013). La bella búsqueda de la autonomía. En Ana Cecilia Dinerstein (comp. ) Movimientos sociales y autonomía colectiva (8-18). Buenos Aires: Capital Intelectual S.A.

Rivera Cusicanqui, Silvia (2010). Ch'ixinakax utxiwa, Una reflexión sobre prácticas y discursos descolonizadores, Buenos Aires: Tinta Limón Ediciones.

Sans, Ana Inés Heras Monner (2012). Pensar la autonomía. Dispositivos y mecanismos en proyectos de autogestión. En Pablo Barbetti y María I. Ortiz (Comps.) Fronteras abiertas de América latina: geopolítica, cambios culturales y transformaciones sociales (463-476), Resistencia: Universidad Nacional del Nordeste. Centro de Estudios Sociales.

Scribano, Adrián (2009). Capitalismo, cuerpo, sensaciones y conocimiento. En Julio Mejía Navarrete (ed.), Sociedad, cultura y cambio en América Latina (89-110). Lima: Universidad Ricardo Palma.

Zubirán, Javier Maisterrena (2013). Creando autonomía en la academia, Seminario "El Proyecto de Autonomía Hoy", PROIMMSE-IIA, UAM, 21 agosto-4 diciembre, (paper).

\section{Revistas}

Almeida, Naomar (2010). Complejidad y Transdisciplinariedad en el Campo de la Salud Colectiva: Evaluación de Conceptos y Aplicaciones. Salud Colectiva, 123-146, Buenos Aires: Universidad Nacional de Lanús. 
Borón, Atilio (1993). Clases sociales y movimientos sociales en el capitalismo contemporáneo. Margen izquierdo. Revista de análisis político-cultural, 8, 7-11, Buenos Aires: Cooperativa Margen Izquierdo Ltda.

Burton, Mark (2004). La Psicología de la Liberación: Aprendiendo de América Latina. Polis, 1, 101-124, México: División de Ciencias Sociales y Humanidades de la Universidad Autónoma Metropolitana.

Castoriadis, Cornelius (1995). La democracia como procedimiento y como régimen. Vuelta, 227: México, 23-32. (Traducción de Aurelia Álvarez Urbajtel).

Costilla, Lucio Fernando Oliver (2008). La interdisciplinariedad en los estudios latinoamericanos: evolución, conceptos y experiencias en la UNAM, Anuario Latinoamericano, 129-139, México: Facultad de Filosofía y Letras, UNAM.

Follari, Roberto (2001). Estudios culturales, transdisciplinariedad e interdisciplinariedad (¿hegemonismo en las ciencias sociales latinoamericanas?), Utopía y Praxis Latinoamericana, 14, 40-47, Maracaibo: Universidad del Zulia.

Kauth, Ángel Rodríguez (2001). La psicología social y la psicología política latinoamericana: ayer y hoy, Psicología Política, 22, 41-52, Valencia: Universidad de Valencia.

Leff, Enrique (2010). Imaginarios sociales y sustentabilidad. En Cultura y representaciones sociales, vol. 5 núm. 9, 42-121. México: UNAM.

Martín-Baró, Ignacio (1986). Hacia una psicología de la liberación. Boletín de Psicología de El Salvador, 5, 22, 219-231, San Salvador: Departamento de Psicología Universidad Centroamericana José Simeón Cañas.

Miranda Redondo, Rafael (2006). Las Fronteras del odio. Reflexión sobre la alteridad a partir de Cornelius Castoriadis. Tramas. Subjetividad y procesos sociales, 24, 229242, México: Universidad Autónoma Metropolitana-Unidad Xochimilco.

(2011). La obra institucional por la autonomía es una historia de migración, Desacatos. 37, 49-66, México: Centro de Investigaciones y Estudios Superiores en Antropología Social.

Montero, Maritza (2004). Relaciones entre Psicología Social Comunitaria, Psicología Crítica y Psicología de la Liberación: Una Respuesta Latinoamericana. Psykhe, 13 (2), 17-28, Santiago de Chile: Escuela de Psicología de la Pontificia Universidad Católica de Chile.

Retondar, Anderson (2008). Hibridismo cultural: ¿clave analítica para la comprensión de la modernización latinoamericana? La perspectiva de Néstor García Canclini. Sociológica, 67, 33-49. México: Universidad Autónoma Metropolitana Azcapotzalco.

Samaja, Juan (2007). Las ciencias cognitivas como transdisciplina. Antinomicidades, 924. Resistencia: Facultad de Humanidades, Universidad Nacional del Nordeste. 
Sans, Ana Inés Heras Monner (2009). Procesos de aprendizaje en proyectos de autonomía: Un marco interdisciplinar para su estudio. IRICE Nueva Época, 20, 89101, Rosario: IRICE-CONICET.

Torres, Daniel Vega (2012). Sobre historia y sociología: interdisciplinariedad y narración en las ciencias sociales en Colombia, Anuario Colombiano de Historia Social y de la Cultura 39 (1), 243-262, Bogotá: Departamento de Historia, Universidad Nacional de Colombia.

\section{Referencias electrónicas}

Boidin, Capucine (2008). Mestizajes y género en las Américas: reflexiones centradas en la sexualidad. Clio, Histoire, Femmes et Sociétés, 27, 169-195. Recuperado 19 junio 2014, de

http://halshs.archivesouvertes.fr/docs/00/57/89/25/PDF/MestizajeYgeneroRevisado.pdf

Castoriadis, Cornelius (s/f). Imaginario político griego y moderno, Recuperado el 2 de agosto de 2013 de http://constituyentes.org/imaginario-politico-griego-ymoderno/ pensamiento de Cornelius Castoriadis. Ediciones Proyecto Revolucionario, 2 (152161). Recuperado el 22 de noviembre de 2014 de http://es.scribd.com/doc/62465348/17/Imaginario-e-imaginacion-en-laencrucijada (2006a). Instituyente (Traducción de Luciana Volco). Recuperado el 2 de agosto de 2013 de:

http://www.socioantro5.blogspot.com.ar/2006/07/instituyente.html (2006b). Poder, política y autonomía. Recuperado 2 de agosto 2013, de http://www.socioantro5.blogspot.com.ar/2006/07/poder-poltica-yautonoma.html

Escobar, Arturo (1999). Comunidades negras de Colombia: en defensa de biodiversidad, territorio y cultura. Biodiversidad, sustento y culturas, 22, 15-20. Recuperado el 22 de noviembre de 2014, de http://www.grain.org/biodiversidad files/biodiv223.pdf Herrera, Mónica (2010). Bourriaud vs. Bourriaud, $3^{\circ}$ Congreso Argentino de Cultura, San Juan, Argentina, 14-19 de septiembre, (paper). Recuperado el 12 de julio de 2014 de

http://es.scribd.com/doc/50100266/BOURRIAUD-VS-BOURRIAUD

Miranda Redondo, Rafael (2010a), Modernidad, psicoanálisis y política. Una reflexión a partir de Cornelius Castoriadis. Riff Raff. Universidad de Zaragoza. Recuperado el 25 de noviembre de 2014 de http://riff-raff.unizar.es/rv10.html 